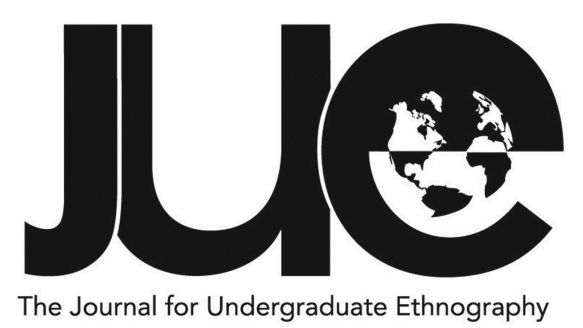

\title{
Getting the Lead Out: Urban Chicken Keeping as Transformative Neo-Agrarianism
}

\section{Sydney Giacalone}

Tufts University , sydney.giacalone@gmail.com

\section{ABSTRACT}

This ethnographic study explores how the discovery of lead contamination in urban chicken flocks in the Boston area unsettles postindustrial optimism and neo-agrarian romanticism, producing new openings for multispecies relationships. Within rising popular and political attention to food systems, urban chicken keeping stands as a uniquely positioned subset of urban agriculture. Through ethnography with chicken keepers, policy makers and businesses in Boston and Somerville, Massachusetts in the summer of 2016, my research investigated how urban chicken keeping might transform keepers' thinking about food systems and animal relationships. The unexpected discovery of lead in chickens' blood and eggs revealed keepers' increasingly entangled relationships with the history of the soil they and their birds live upon, exposing what Marx (1981) termed the "metabolic rift" at the heart of industrial capitalist approaches to subsistence. With lead breaking the imagined simplicity of urban agriculture and the linear progression of modern cities, responses in urban chicken keeping reveal space for new ways of thinking about collective metabolism, multispecies living, food politics, and the bodies wrapped up in these material legacies.

Keywords: chickens, urban agriculture, food, multispecies 


\section{Introduction}

Over the past decade in the Boston area, a rise in residential chicken keeping and discourse around "green," "postindustrial" cities has prompted the growth of businesses, community networks, and city policies focusing on urban agriculture. The practice of urban chicken keeping complicates many of the binaries on which modern industrial society has been constructed: the separation of the human from animal, city from country, industry from nature, and pets from livestock. Both cities and keepers have entered this scene by constructing imaginaries-conceptions imbued with ideals and assumptions-of what modern urban chicken keeping entails and what I term "urban neo-agrarianism." Through ethnographic observation and interviews with chicken keepers, policy makers, and business owners in the cities of Somerville and Boston during the summer of 2016, I examine the recent construction and already visible breakdown of this urban neo-agrarian imaginary as keepers' experiences necessitate responses and reconceptions of what urban animal agriculture may entail for keepers, animals, and larger civic participation.

My research aims to understand the responses of keepers in these supposedly postindustrial cities to the recent revelation that the historically lead-contaminated soil in their yards is contaminating their eggs and birds' bodies. In effect, lead has broken through the supposedly neat, linear progression of these cities' past and present ecologies - from dirty to clean, industrial to post-industrial - that is presented by urban agricultural advocates. With this material evidence of the city's industrial history cycling through its many species of inhabitants, what is our willingness to know and truly act upon the history of the cities we live in, and the food and animals we live with? 'This paper will examine the resulting responses as a way to think about the potential for urban animal agriculture to generate a truly transformative politics around food, urban ecology, multispecies relationships, and the task of remediating embodied legacies of industrial capitalism.

\section{Methodology: Scratching Around in the Chicken Yard}

To conduct this research, I used ethnographic observation, in-person interviews, online surveys, and photography of Boston and Somerville chicken keepers, urban agriculture business owners, and city officials involved in each city's recent policy process. I recruited chicken keepers by posting on Facebook groups for Somerville and Boston urban agriculture communities. I also recruited participants through the networks of keepers I interviewed who wanted to connect me with their chicken keeping friends. This snowball sampling worked well and quickly in such a highly networked community. However, because my initial contacts belonged to the largely white, middleclass portion of the cities' total chicken keeping population, as well as because of language barriers, I was unable to access other groups of chicken keepers such as the immigrant keeping community in both cities. (The limits of this divided network and resulting lack of access to immigrant chicken keepers are discussed further in the article.)

In total, I gathered data from 15 keepers, three business owners with companies directly serving keepers, and two city officials (one in each of the two cities). For the chicken keepers, seven interviews were conducted in person and eight interviews were conducted through an online Google Doc survey. Both the in-person interviews and the online survey included closed and open-ended questions. Interviews with keepers focused on their reasons for getting chickens, experiences since having chickens, personal relationships and daily routines with their chickens, political participation in their city's activism around chicken keeping, and personal politics around food systems participation. For city officials and business owners (most of whom did not own 
chickens themselves), interviews focused on the creation of policy or business models to serve the urban chicken keeping scene, political participation in the chicken keeping debates in their city, reasons for being a part of this scene, and experiences interacting with keepers. Additionally, I took photographs and detailed fieldnotes during and after each interview site visit to participants' houses and businesses (see Figure 1).

During analysis of my interview transcriptions and fieldnotes, I coded excerpts based on key themes and organized emerging findings through this method. Due to the complex legal issues of this practice, along with the potentially controversial opinions expressed, I chose to assign all participants pseudonyms in final products of my research. A methodological note is necessary regarding the controversy around the issue of lead. While I was conducting my research, the Cummings School of Veterinary Medicine at Tufts University was at the same time conducting a study on lead in chickens and eggs (discussed below). I was not involved with the Tufts study, but it included many of my research participants. Thus, I positioned myself as an ethical researcher within this scene by providing my participants with information about the Tufts study and encouraging them to participate in both studies in order to assess any health risks they may have been facing. In the following sections, I trace the background of my research scene and my overarching findings before focusing in on my participants' responses to the issue of lead within their urban chicken keeping practice

\section{Relocating Urban Animals in Somerville and Boston}

The Boston area provides an important case study for the growth of urban agriculture, particularly the city of Somerville, which lies on the north side of Boston's metropolitan region. The densest city in New England, Somerville has a population of just under 80,000 people in four square miles. In the nineteenth and twentieth centuries, both Somerville and Boston were centers of financial, educational, and material production characteristic of the industrial era. In the later part of the century, these cities

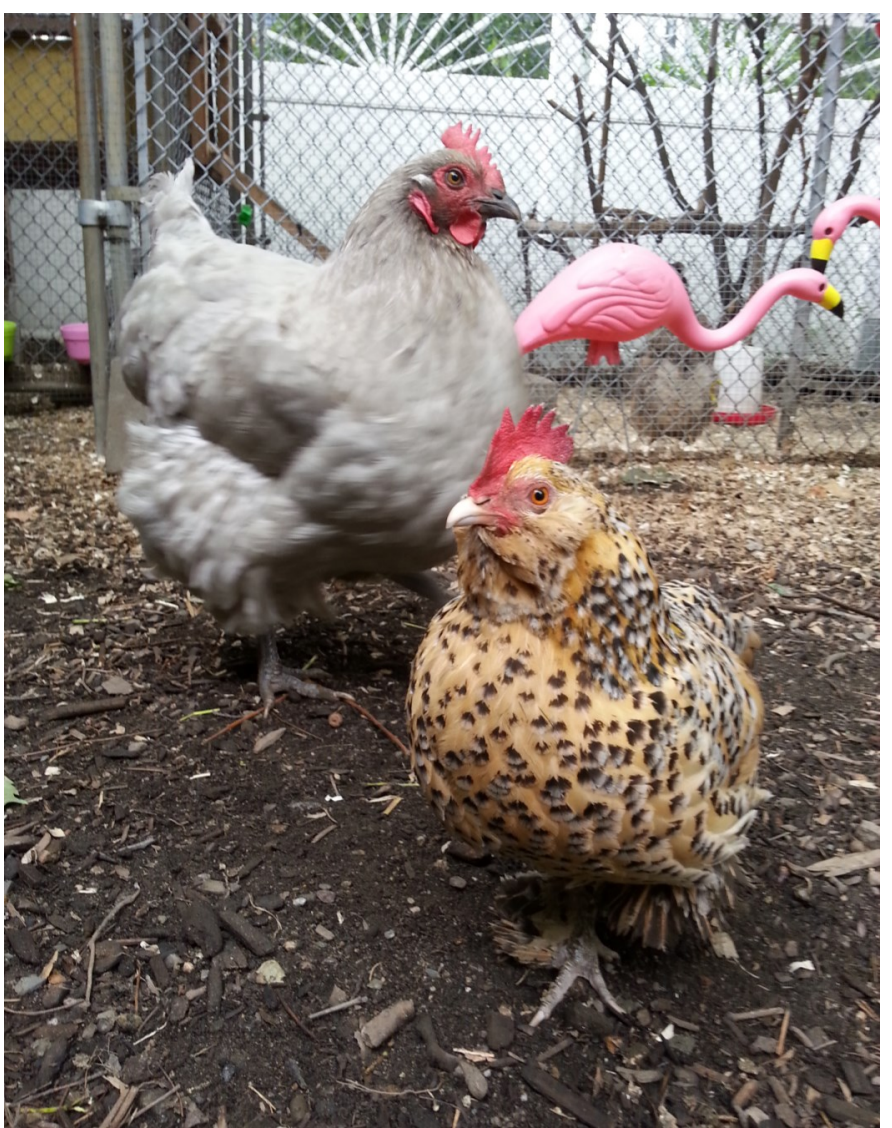

Figure 1: Opal and Tangerine, two of the 47 chickens I interacted with during my research fieldwork. Photo by author.

experienced deindustrialization, shifting from industrial-driven economies to spaces of industrial and capital flight, and then to what many scholars describe today as postindustrial life (Bluestone and Stevenson 2000). Boston has been described as "the exemplary postindustrial city" in its revived economic vitality and its redevelopment founded on knowledge production at the turn of the twenty-first century (Ward 1998 cited in Stanton 2017, 251). In cities that underwent this shift, contemporary policies can be seen to promote a "postindustrial" urban mindset, encouraging images such as the "green" or "smart" city. This mindset assumes that the industrial is part of a city's past, and that the past has already been dealt with by the city remediating the worst evidences of brownfields and abandoned factories.

With the twenty-first century's rising trend of local food production and consumption, the latest in a historic, cyclical pattern of "back to the land" food movements in the United States, many cities have embraced urban agriculture as part of this urban postindustrial vision. Nationally, urban municipalities are making 
strides in their planning and public health departments to promote the creation of community gardens, local farmers' markets, and school growing programs (Voigt 2011). These projects aim to promote healthy eating and local economic development while bolstering an image of their cities as "green", innovative, and clean spaces that have moved past their histories as industrial centers.

Urban life and agriculture have shared a close partnership since the emergence of the city. It was only through agriculture and the food trade it enabled that cities became possible, with early cities developing along the geography of fertile land. Through the nineteenth century, daily markets selling food within the city were commonplace and often included the sale and slaughter of live animals that were brought to the city from rural and peri-urban places (Steinberg 2002; Moore 2006). This normalcy of animals in urban space faded in the early twentieth century as a result of zoning restrictions and changing cultural norms regarding urban human-animal proximity, marking a cultural and legal shift away from productive animals within most modern cities of the Global North (Steinberg 2002; 161). While urban livestock keeping has continued quietly in some communities, including among formerly-rural immigrant populations, most city residents and their governments have come over the past century to consider productive animals and the broader cultivation of food out of place in urban contexts.

Recently, municipalities across the country have increased the scope of their urban agricultural promotion by creating or revising land use ordinances to allow for keeping productive animals, such as chickens and bees, within city limits (Voigt 2011). Somerville and Boston are two such municipalities, and Barth's article in the popular online journal Modern Farmer asserted that "combined, Boston and Somerville may be the most urban agriculturefriendly metro area in the country" (2015, n.p.). Striving to market themselves as centers of progressive urban agriculture, both cities have developed policy mechanisms to structure urban agriculture within their bounds by providing regulatory policies or recommendations. Without explicitly encouraging residents to get chickens or grow gardens, both cities' policies are quite favorable to urban agriculture, letting residents do as they desire in accordance with these policies and providing assistance through workshops and online guides.

The City of Somerville legalized chicken and bee keeping in 2012 through an Urban Agriculture Ordinance that provides regulations on the number of birds and coop size and requires a $\$ 50$ permit. The city's ordinance was the first of its kind in New England, an impressive feat for the region's densest city and one that reflected the politically progressive character of much of its population. Along with the ordinance, the Mayor's Urban Agriculture Initiative created an "ABC's of Urban Agriculture" book to make the policies accessible to residents. A city official who had helped write the ordinance cited overall interest in local food, the mayor's community health initiative Shape up Somerville, and the fact that city residents were already engaging in animal agriculture as motivations for the ordinance and its inclusion of bee and chicken keeping. This official noted that while large-scale impacts of urban agriculture such as urban food security are not likely to be addressed by the scale of urban farming in Somerville, she sees motivation for the city's urban agriculture in:

[a] lot of intangibles, and those are community-building and people getting to know their neighbors and all of the benefits that come around food and local food and sharing food. So the vision really is about creating a network of local food sources and then [the] community-building [that] comes from that is a bonus.

While the city government considers these permits a way to guarantee protection of keepers' rights if neighbor disputes occur, my research shows that many Somerville keepers feel the permits are unnecessary and choose to keep their chickens without acquiring a permit.

Boston's 2013 Article 89 which revised the city's zoning code to allow for urban agriculture was a more complicated process. Boston is not zoned as one individual city but rather as 


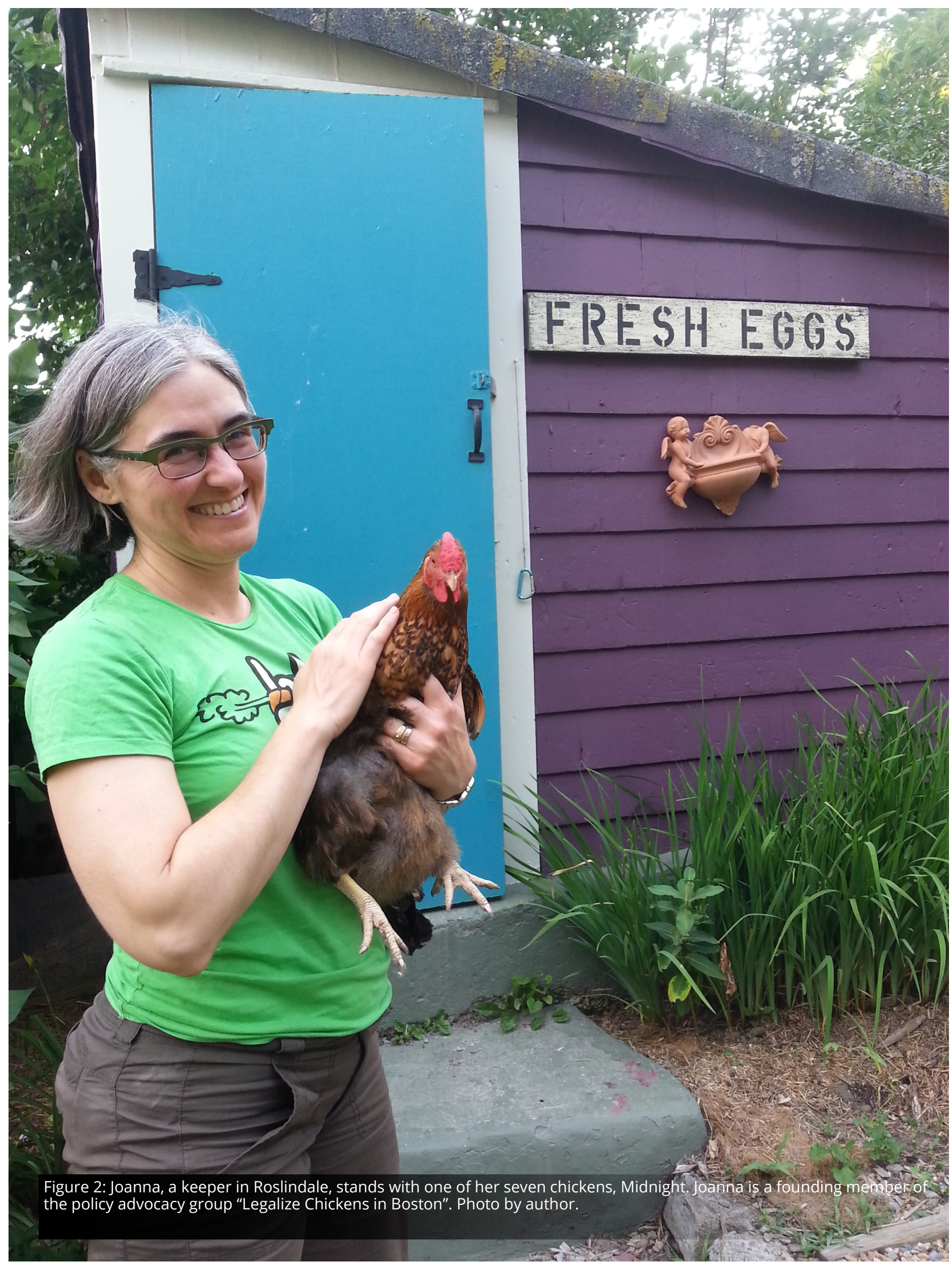


several independently linked neighborhoods with somewhat autonomous senses of identity within the larger metro area. As such, some of the changes Article 89 made to the city's urban agriculture policies came as recommendations rather than definitive rulings for all parts of the city. In the case of bees and chickens, Article 89 provides recommended practices but defers to neighborhoods' individual policies on the legality of urban livestock, which most neighborhoods have labeled as a "forbidden" and therefore illegal land use since the 1930s. Several participants in my research were involved in Article $89 \mathrm{~s}$ community input process during the summer of 2013, and they expressed disappointment at the rezoning's silence on what they see as antiquated neighborhood policies forbidding productive animals. Joanna, a keeper living in the neighborhood of Roslindale (see Figure 2), contextualized the difficulties associated with Boston's process as part of the historic break between animals and urban space:

It was the old zoning [that] had something about no livestock, and that was put in place back in the 1930s when there was livestock everywhere and it was a problem. It was a problem with disease and you know. So they said "We need to put the farms out in the country. We'll bring the food into the city.... We're not going to be raising our own, we're not going to be slaughtering our own animals in the city," you know. So they tried to clean up the city by getting rid of all the animals, and the horses... It's like cars come in and no more horses; they clean everything up. And so that was on the books.

As such, most chicken keepers in Boston are not practicing their particular form of urban agriculture in accordance with the law. However, Boston keepers and city officials involved in the rezoning recognize a de facto agreement between the city and its residents: keepers are told both directly and indirectly to go about their practice in a responsible manner to avoid neighbor or sanitation conflicts, and the city allows the practice to continue and even grow. Some keepers referenced notable exceptions of keepers they knew who were forced to get rid of their chickens after neighbors' complaints or sanitation violations, though these instances were not thought to be common. Several participants in this research were or still are part of a group known as "Legalize Chickens in Boston," though most describe the legalization efforts of this group as having "fizzled out" in favor of continuing the current de facto system.

\section{The New Urban Chicken Keepers and Their Practices}

The demographic profile of keepers reflects the demographic findings of other recent research on this New Urban Chicken Keeper or "NUCK" population (Blecha 2007, 39). The majority of the keepers I interacted with were middle- to upper-middle-class white women between the ages of 30 and 60 . These demographics reflect the ways the broader "food movement" around local and sustainable food is currently raced, gendered, and classed, as well as how nonwhite and low-income participants in modern alternative food production are often made invisible (Alkon and Agyeman 2011). Many keepers and advocates made remarks that showed a conceptualization of themselves as the "others" of their city's immigrant chicken keepers. Often this group of keepers was imagined as within a nonspecific "immigrant" category, though individuals referenced particular communities in the city such as Haitian, Portuguese, Brazilian, Chinese, and Vietnamese residents. They spoke of immigrant chicken keepers as living closer to the land and being more "authentic" and agrarian, more likely to be male, but potentially less humane and hygienic. One Somerville keeper referenced an immigrant friend who knew how to kill a chicken and was "happy to...do the deed" when the keeper did not want her birds after laying age. Another keeper expressed worry that immigrant families who had kept chickens in other countries may keep their birds here "improperly housed" and not spend the time or money the keeper felt was needed to keep chickens "responsibly" in Boston. Likewise, city officials and other proponents of chicken keeping spoke of immigrant populations 
involved in this practice both as positively "closer to agriculture" while also questioning their assumed motivation of eating the birds, in contrast to what these proponents characterized as the "white," "fresh food movement," and "socially, environmentally conscious type" of keepers. Implicitly, the construction of the urban chicken keeping demographic conveyed by many in this scene draws from norms of whiteness, American agrarian nostalgia, and privileged economic positionality, forgoing or invisibilizing the multicultural reality of urban chicken keepers.

Several additional patterns emerged through this research that combine to reveal the urban neo-agrarian imaginary constructed by these New Urban Chicken Keepers and their proponents. First is the common conceptualization of the practice within contemporary food discourse. In addition to positioning themselves in conceptual opposition to immigrant keepers, the keepers and advocates I interviewed also located themselves as the "others" of industrial agriculture which they see as globally dominant, inhumane, and disconnected from consumers and food itself. All the keepers I interviewed cited a desire to produce local eggs to eat and reduce their reliance on conventionallyproduced food as a primary or partial motivation. Linda, a Somerville resident in her early fifties, who teaches English to area immigrants, began keeping chickens in 2012 in order to be true to her values of ethical vegetarianism and "trying to be low impact on the planet." She sees her practice as the only way to truly know she is consuming eggs "humanely" compared to "an industry that treats animals cruelly" or even a local farm where she feels conditions are still not transparent enough. For Mary, another Somerville resident in her fifties, keeping chickens as pet-like companions was more of an initial motivation than producing local eggs as an alternative to conventional sources. However, Mary states that keeping her birds the past three years has made her more conscious of the benefits of raising seasonal, unprocessed foods while also living what she sees as a modern urban lifestyle. "I like having the [egg] source be very local. I like the fact that I'm not contributing to factory farming in one teeny tiny little way... I really love the fact that I'm able to do that and still live in the city, which has a lot of other benefits."

Local food system participation, environmental consciousness, and a political stance against factory farming all while living a modern urban life are thus three facets of what constitutes urban neo-agrarianism for these participants. In addition, a pattern emerged when considering the practice within broader terms of community development and social health. Those involved in chicken keeping in Boston and Somerville have a strong network: many referred in their interviews to others I had met as key players in this growing community. Nearly all keepers I spoke to had attended one if not several educational or social events arranged by these key players, where they were able to meet other keepers and discuss current legislation or research on chicken keeping in the cities. Joanna, a keeper in the neighborhood of Roslindale, referred to the spread of the practice as a "community builder" both internally among those who kept chickens and externally with those who interacted with the practice as intrigued neighbors. Chicken keeping is also spurring connections between residents and city officials, as many keepers referenced developing personal relationships with officials in planning, sanitation, and health departments because of their experiences dealing with regulations associated with the practice. Keepers had diverging views on where promoting urban agriculture fell on their communities' agendas, with some feeling that the practice was vital to strengthening their community while others thought that it fell below more pressing concerns of gentrification and violence. However, participants agreed that community development was an aspect of chicken keeping that was having more significant and positive impacts in their lives than they had expected.

The primary area where keepers diverged rather than agreed on their practices was in characterizing their personal relationship with their chickens. The fifteen keepers involved in this study span the spectrum from considering their birds to be livestock to seeing them as pets. This was assessed both by direct 
questioning and by looking at indicators of their care and investment in birds, such as naming them, showing attachment to their personalities, and investing time and money in their health (see Figure 3). Rather than situating the relationship at one extreme or the other, the majority of keepers chose a specific spot along the continuum based on their initial motivations and subsequent experiences. Debra, a Roslindale keeper in her sixties, considers her birds closer to the livestock side of the scale, though she notes, "[t]hey definitely have personalities, but they're not like the cat. You know, they're kind of...chicken. They're fun and they're entertaining, but I wouldn't say they're like pets really." Mary first considered her birds in the middle of the spectrum, but her investment in their health over the past year has caused the birds to move "a little further along on the pet scale" because their care at the veterinarian feels like "more of a pet model than a livestock model" to her. Linda exists on the far livestock side and contrasts herself with keepers who treat their birds emotionally and medically as pets. "That's not the case for me. I have them to give them a good life so they live a decent life in good surroundings and they produce eggs and that's the deal."

Some participants made statements that showed a budding linkage in their minds among these various aspects of urban chicken keeping: the environmental, food-focused side; the community development side; and the individual bird-to-human relationship side. John, a Boston resident in his forties, opened a store several years ago to cater to the area's growing need for urban agriculture supplies and knowledge exchange. John sees the crux of practices like urban chicken keeping as not totally about food itself: "I think the idea that I like about urban agriculture is that it connects people and makes people more aware of the earth, what sustains them." Here, John hones in

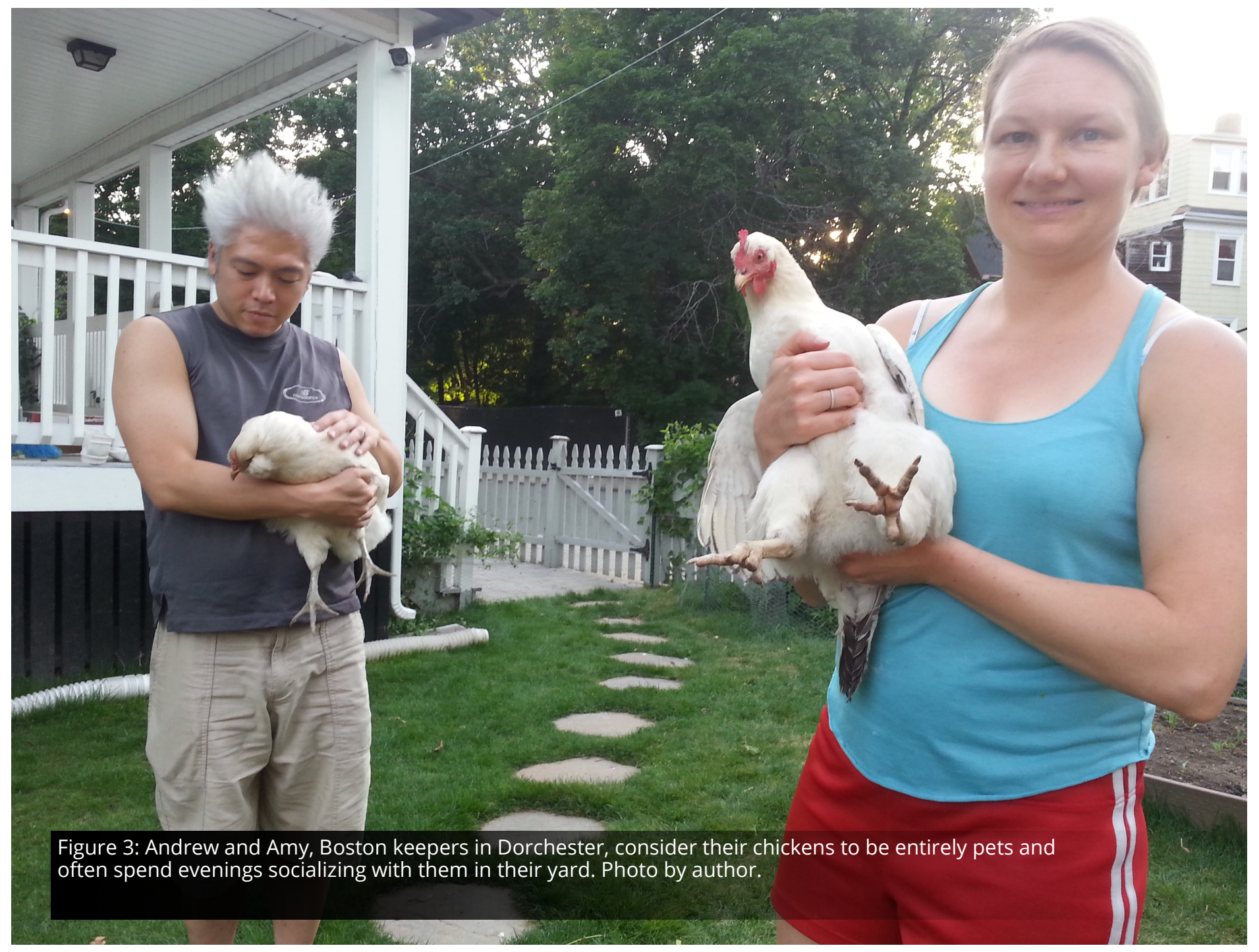


on a common theme that I identified in many keepers' experiences: the practice of keeping chickens never involves just keepers and their chickens. Keepers became more aware of hawks, raccoons, and neighbors' dogs in the constant battle they waged as defenders of their chickens, as well as becoming more aware of the other species of birds that called their yards home. Even within the supposedly controlled ecology of the city, keepers could not invite chickens into their spheres without also inviting sparrows and cardinals, a fact keepers like Mary begrudgingly accepted when the norm in her coop became her four hens plus dozens of sparrows. Through their practice, keepers came to realize that their relationship with their birds was not simply a chicken-tohuman singular relationship but rather that they were cultivating relationships of care, mutual acceptance, or animosity with many species in their yard's ecology.

\section{Conceptual Framework: Multispecies Response to the Metabolic Rift}

To understand interactions like these among many different kinds of bodies, recent scholarly approaches strive to decenter the human in exchange for a more multispecies perspective. A primary aim of a multispecies approach is to recognize and let flourish our interconnectivity and mutual becoming with the many species around us-our "knots of species coshaping" (Haraway 2007, 42). Haraway describes this goal as "becoming worldly with others" or "autre-mondialisation" (2007, 3). Nading describes this using the concept of entanglement, a process of "the unfolding, often incidental attachments and affinities, antagonisms, and animosities that bring people, nonhuman animals, and things into each other's worlds" $(2014,11)$.

Within this scholarship, there is considerable debate over whether the domestic sphere is a solution or a curse for multispecies flourishing. Some perspectives point to multispecies relations within the home as the most productive relationships to cultivate new types of flourishing (Haraway 2007; Rudy 2011). Others urge us to move outside the domestic sphere's problematic confinement of care where "our species being is realigned to stop Others at home's door" (Tsing 2012, 150-151). It is here that urban chicken keeping within yard ecologies pushes this debate to question conceptions of the domestic itself. Urban chicken keeping shows that seams of species cohabitation and co-place-making exist within and around the walls of the supposedly humanonly (plus perhaps a dog or cat) domestic sphere, breaking down the very definition of the "home" to include the complete multispecies ecology in and around the home. Home is where we are, where we flourish, and where we can enact embodied care and placemaking with others more accessibly and particularly than anywhere else. Keepers show that a multispecies understanding of the home means this place is not defined by lines of domesticity but by the fluid knots of entanglement that make up the places that ground us. Coming to an understanding of the fluidity of species within our "home"-realizing the seams that exist not in far-off margins but right here at home, making domesticity itself an illusion-changes the definition of the "home" to a post-domestic ecosystem of worlding between species.

Given this multispecies approach towards decentering the human and recognizing that our becoming is interconnected with others' becoming, it is also necessary to ask what those interconnections are made of, for which the theory of metabolic rift proves useful. Metabolic rift is a Marxian (1981) environmental theory used by scholars to explore the material and conceptual breakage points in our global food system and industrial capitalism more broadly. Geographer McClintock summarizes Marx's argument in saying that

the development of capitalism
(and the urbanization that
followed) alienated humans from
the natural environment and
disrupted our traditional forms of
'social metabolism', the material
transformation of our biophysical
environment for the purpose of
social reproduction. $(2010,1-2)$

McClintock traces out how the industrialization and globalization of the food system, occurring 
in conjunction with the rise of the industrial city, caused metabolic rifts-breakage points-all along the food system. Ecologically, industrial agriculture practices cleaved "a biophysical rift in natural systems (such as nutrient cycles) leading to resource degradation at points of production and pollution at points of consumption" (McClintock 2010, 2). These ecological rifts specifically rely on "spatial and temporal 'subsidies' to the food web", the term "subsidies" referring to the unpaid, unacknowledged, or unjustly-distributed costs created through these large scale industrial processes (McClintock 2010,4). These patterns were set in motion with the late-eighteenthcentury rise of market-based agriculture, land enclosures, and increasing mechanization of food production, and have only expanded over time. Now-global practices such as monocropping, intensive use of fossil fuels and chemical fertilizers, and movements of nutrients from Global South stores to the depleted Global North all constitute the dominant food system that New Urban Chicken Keepers seek to escape or transform.

The lens of metabolic rift provides a way of thinking about this total scene as one interconnected set of material, social, and economic processes of transformation, ruptured by the kinds of efficiencies and distances that industrial production enables. The bodies of humans, animals, plants, land, and water, and the nutrients and energy that circulate through each are all part of the same metabolism. What if the city was looked at as itself a body, a combination of all of the nutrient and energy flows both within it that have been imported from elsewhere to help create it? This requires a significant decentering of the human to consider ourselves as not the authorities over clean urban cycles but rather one cog in a larger urban-natural metabolic wheel. Applying this multidimensional lens of metabolic rift to scenes of urban agriculture today, it becomes clear how historical processes are materialized in the water, soil, and bodies of those attempting to heal the material, social, and economic legacies of industrial capitalism.

The remainder of this paper will focus on what I found to be the most controversial evidence of these legacies: the lead found in many of these chickens in an unpublished 2015 pilot study conducted by the Cummings School of Veterinary Medicine at Tufts University. Though keepers and researchers may consider the discovery of lead in their chickens and eggs to be a potential breakdown of their practice, the idea of metabolic rift and a larger urban metabolism shows that the lead discovery is less a breakdown itself than an index of the breakdown that has already been happening within the fuller timeline of urbanization, industrialization, spatial displacement of this industrialization, and massive displacements of nutrient and fossil fuel energy cycles along the way. This breakdown has been and still is an ongoing, slow crisis precipitated by industrial capitalism. It is embodied conceptually in our dominant food system and the alternatives proposed to reform it, as well as physically in the bodies and soil such as those in the stories told here. The costs of this crisis are still being accumulated and subsidized even while they are being recognized, a recognition growing popular in current sustainable food discourse, to which many of us respond to by trying to alter our relationship with food. The chickens here are taking into their bodies, and then into human bodies, a part of the city's-and the modern world's-history through the soil. The resulting responses of chicken keepers to the identification of lead in urban birds, which I discuss below, are in some ways crippling the wildly-held urban neo-agrarian ideal and requiring the research participants to realize that food system participation and change cannot build up from the ground while ignoring what is in the ground.

\section{Discussion: Lead as a Catalyst for Response}

Although I did not know about lead in chickens when I began my fieldwork, the theme arose quickly in interviews, pointing to this developing situation as an area worth further inquiry. Many of my participants had been involved in or heard about the 2015 Cummings pilot study and told me about their experiences grappling with the study's results. During the summer of 2016, as I conducted my interviews, a larger version of the Cummings study began and I was able to connect keepers who had not had 
testing done during the pilot study to the new study if they desired to participate. As such, the lead situation and resulting responses became a central avenue for analysis in my study in the fall and winter of 2016.

As a disruption in the expected relationship between keeper and chicken, lead provides a catalyst for multispecies response. Haraway $(2007,36)$ states that the first step in opening oneself up to becoming worldly with and accountable to other species is simply curiosity, an "unsettling obligation... which requires knowing more at the end of the day than at the beginning." . From curiosity stems touch, which "ramifies and shapes accountability...it peppers its partners with attachments sites for world making" (Haraway 2007, 35-36). Finally, from accountability stems responsibility: "[o]nce we know, we cannot not know. If we know well, searching with fingery eyes, we care. That is how responsibility grows" (Haraway 2007, 287). This is where possibility for truly new forms of multispecies relationships lies: taking seriously the knots entangling all those implicated in urban chicken keeping demands a response. The keepers, policy makers, business owners, chickens, and every other animal that moves and lives through these yards are "looking back at each other, sticky with all their muddled histories" (Haraway 2007, 42). The question becomes: how do these different groups respond?

Some respond with disconcerting ambivalence. Linda was forced to grapple with this question when she participated in the pilot study three years after getting her chickens. When her birds' blood tests came back as testing moderately high for lead-lower than some of her friends' birds' results, higher than others'-she asked the researcher to also test her birds' eggs. The results indicated that Linda's eggs had the highest levels in this area, a particular issue of safety for Linda who lives with a health condition that makes ingesting lead more dangerous than for the average adult. She hypothesized that her high egg lead levels were due to her coop's proximity to three different houses and the chipping of past lead paint, though she noted that her soil tests came back as only moderately contaminated compared to others' highly contaminated soil.
Linda responded by taking "action to get rid of my chickens at that point," giving the contaminated birds away to a family friend who had a farm, replacing the soil under their run, and getting four new birds who are confined to this patch of remediated run rather than let out in the yard as the previous birds were (see Figure 4). This response appears to stem most directly from Linda's consideration of the birds as livestock animals for the production of eggs; once the birds were unable to produce eggs that were safe for Linda and her husband to consume, the birds were not considered worth the financial and energy investment for veterinary treatment or the emotional investment of keeping the birds simply as pets. She said of the newly confined birds: "I may let them out from time to time, but that soil's lead contaminated...So I'm not sure it's a great idea." While Linda states that her original and continued motivation for keeping chickens is ethical animal treatment and vegetarian consumption, "to provide them a decent life in good surroundings," the true weighing of her birds' worth in this arrangement is called into

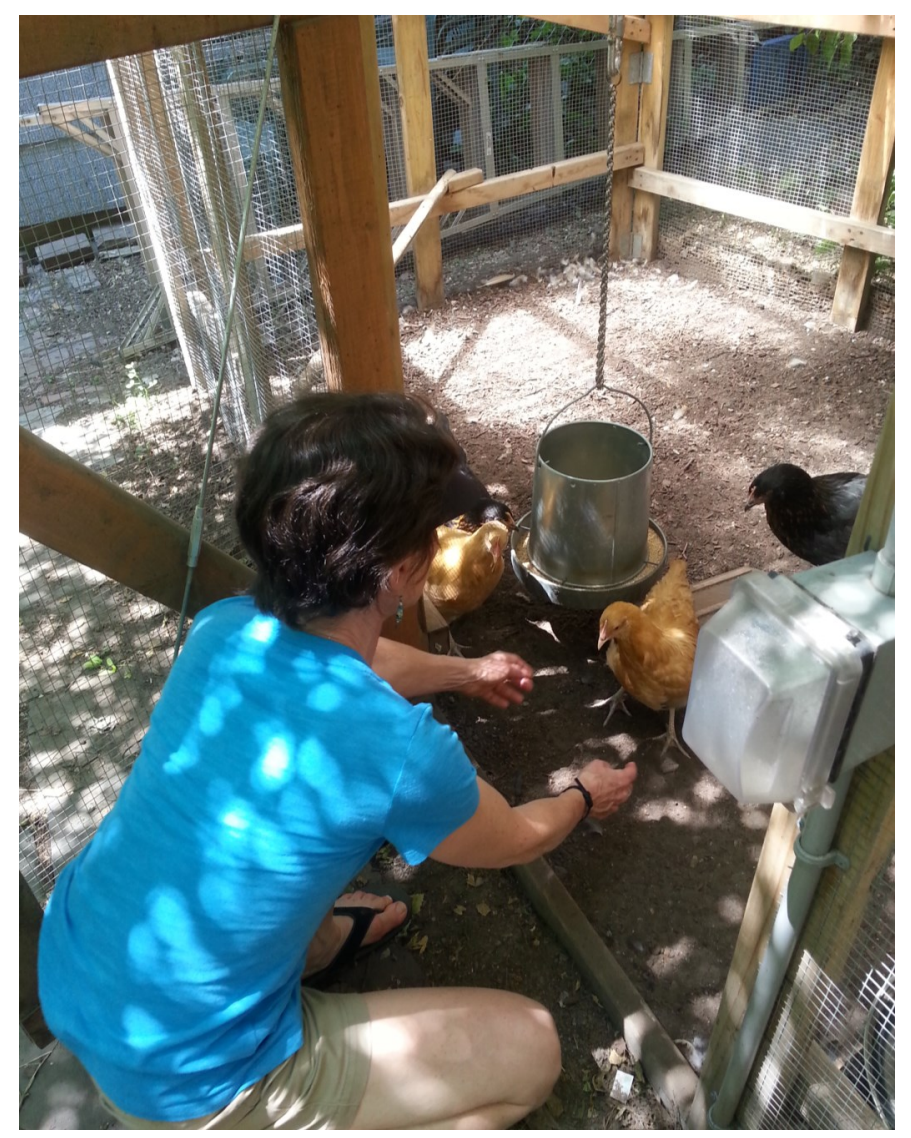

Figure 4: Linda reaches for her chickens inside their new enclosure, where the birds stay permanently now to reduce risk of lead exposure from the rest of the yard's soil. Photo by author. 
question. Linda exemplifies the side of urban chicken keeping that wants to respond to breaks in the conventional food system but is unable to consider what a deeper response to this multispecies metabolic relationship might mean: a decentering of herself in favor of a more serious sense of responsibility for the birds that she brought into this yard as a participant in industrial capitalism, which began a series of multispecies codependencies in which she no longer wants to fully engage (Nading 2014, 11).

At a meeting last year of the pilot study's researcher with its participants, Linda gave suggestions for the next phase of the study (still in progress as of early 2017). She has been recruiting keepers for the study, saying, "I just feel like people should know what's going on." She feels that the responses she has received have been less than satisfactory, as she stated "I was actually surprised; I thought I would get more people [interested in getting lead tests], but some people didn't want to know, some people's chickens weren't laying right then, and various reasons." Linda's surprise at what she has observed as ambivalence or non-response from others is intriguing when contrasted to her own ambivalent statement on the Somerville community's knowledge about overall lead-contamination in the soil-"[w]e know soil is bad in Somerville generally"-and an ambivalent remark during our interview when she commented that she was feeding her birds clover that she believed could be contaminated with lead. I saw similar ambivalence in other keepers when I told them of the Tufts study and encouraged them to get these free lead and salmonella tests. Some pursued participation and others did not, with one interviewee enthusiastically telling me they wanted to get testing done but not following through in the months after our meeting despite frequent following up on my part.

Others responded with a greater sense of interspecies responsibility and solidarity. Mary had participated in the same pilot study in 2015. Two of her four birds, all asymptomatic, were given blood tests for lead, both coming back as significantly high. This was consistent with the overall results of the study: many hens tested had higher blood lead levels than expected, but variation within and between flocks was high and no birds were symptomatic at the time of testing. Three weeks after these tests, Mary noticed one of the chickens with an enlarged crop and watery stool. "And then one morning-and this was the event-she was staggering."

Mary responded by investing substantial resources of money and time in treating her chickens for lead poisoning through a vet outside the city. As she felt "it doesn't really make sense to treat them unless you're going to fix the soil," Mary and her husband also remediated a majority of their yard's area with new soil (see Figure 5). To Mary's dismay, several of her hens have exhibited reoccurring lead poisoning symptoms over the past year due to lead from the initial contaminated soil still releasing slowly from their bones, requiring subsequent treatments. I asked Mary how she weighed the decision to treat her chickens rather than "re-home them," as she mentioned Linda (whom she had met during the pilot study) had done.

\section{I think if I had known what a big drama it was, maybe it would have given me pause. But it really...it's one of those things that's like your pets are sick and so you will pay what you would kinda pay to fix them...And you know, in part their lead poisoning is because of me, right? It wasn't intentional, but it's because they're in this environment.}

Mary exemplifies the cyclical nature of care and multispecies response that Haraway (2008), Tsing (2012), and Nading (2014) envision: incidental attachments in the form of pet-love bring Mary and her chickens into each other's worlds. Once the birds' space of living overlaps with Mary's, she feels an interspecies responsibility to maintain that shared home's ecosystem. For Mary, taking seriously the chickens' existence in this space and what brought them here "engenders forms of identification and companionship that contrast to hyper-domestication and private property as we know it" (Tsing 2012, 142). Her indexes of care and investment in these birds' bodies- 


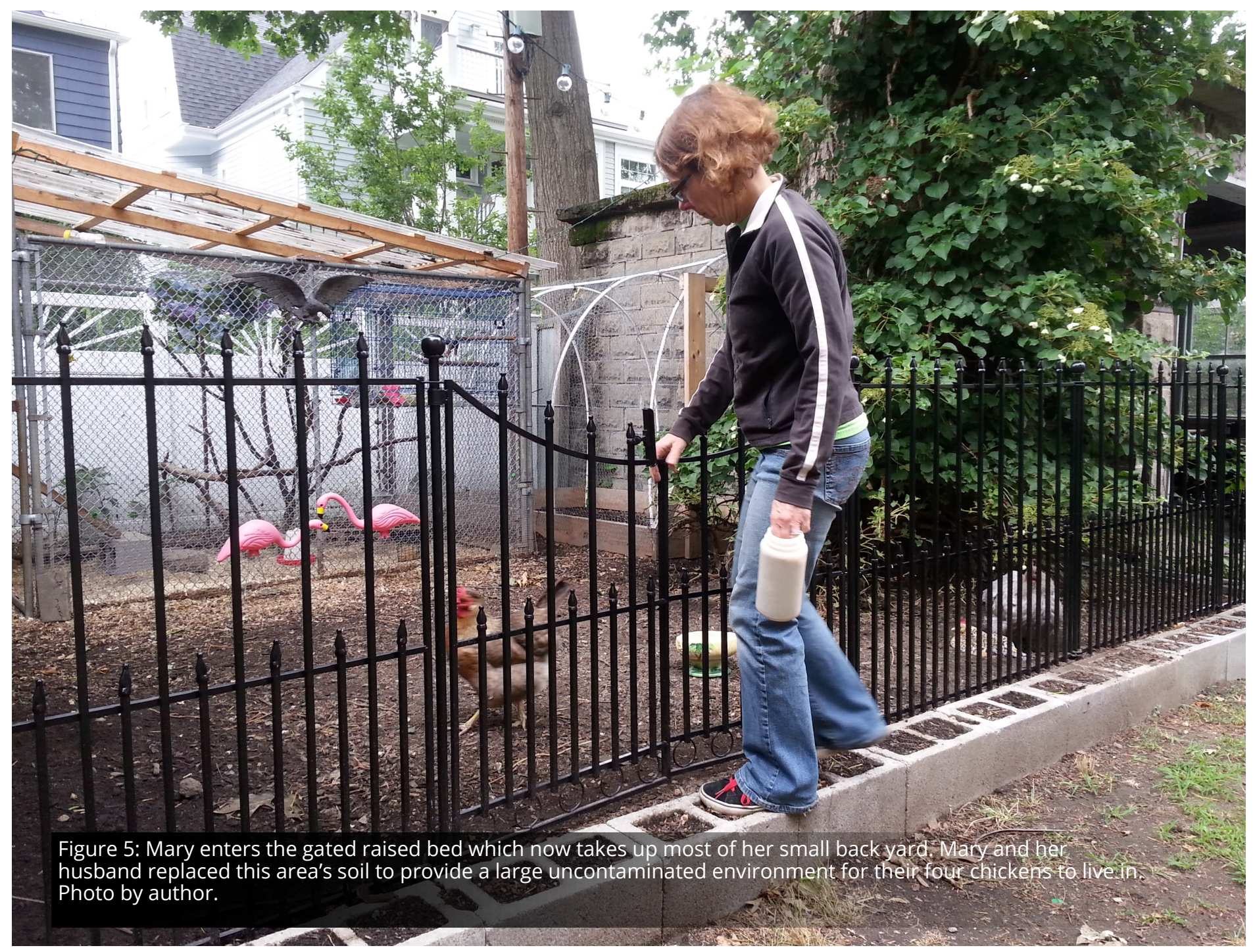

lives themselves worthy of response outside their worth as providers of food or affectionhave clearly grown because of this lead situation. Mary's response seems to reflect a budding awareness of her life and environment being part of the same urban-natural metabolism as her chickens. She faces their lead poisoning with a sense of responsibility for their introduction into this historied urban environment through investments of interspecies solidarity in the yard's soil and the chickens' bodies which have ingested its legacies.

Like Linda, Mary acknowledges that it is a known fact that there is leaded soil in Northeast cities, but says she has not heard it discussed as something to consider when keeping chickens as opposed to its common discussion in urban gardening. Animal agriculture seems to have pushed this conversation into more nuanced, though uneasy, territory in a way that vegetable agriculture did not when public discourse characterized lead in urban gardening as a predictable but manageable factor to be put to rest through raised beds. Mary has thought of ways to spread her story, but she worries about the possible effects of this message.

I guess I don't want there to be kind of a weird hysteria about chickens and lead. But maybe people are a little less worried about it since lead in the environment is kind of something that they know about already...I certainly wouldn't want other people to have their birds suffer and possibly die because of something like that. So I guess that's more important to think about than whatever negative things could come of it. Cause it kinda just is, it's not a judgement, 
it's just... There is lead in the soil.

Even with this internal dilemma, Mary feels complications come with the territory of urban agriculture. In discussing how her chickens have affected her thinking about food, she stated:

I think [keeping chickens] has changed [my relationship with food] and has made me more aware of it, but also, you know, it's complicated right? Like it's fun to have chickens, but it's certainly not without expense, and, you know, the whole lead drama has really... You know, it was a lot of work. And I feel like anybody who goes through the undertaking of getting some kind of livestock is going to have some kind of drama. You know, health crisis, or if they get goats and then there's babies... It's not like they just take care of themselves.

Here, even Mary, a keeper who demonstrates a unique multispecies solidarity and willingness to take responsibility for remediating small bits of metabolic rift, displays a normalized level of ambivalence towards the lead situation she and her fellow keepers are grappling with. Over the past year, she has reconciled daily with the complicated history that brings her backyard animal-human encounters into existence, but like many participants, she can be understood as harboring some level of discomfort about the fact that this metabolic relationship was something she had not intended to grapple with as deeply as she now is.

Debra's response contrasts with both that of Linda and Mary in that she chose to change nothing about her practice of keeping chickens and eating their eggs after receiving positive chicken blood tests in the 2015 pilot study. Debra recalled "[i]t wasn't clear from his study what that meant. You know, whether it went into the eggs or not. So I just left it at that." Just a week before our June 2016 interview, Debra had researchers from the next phase of the study test her eggs, soil, water, and feed. She expected results back within a month, though she had not received them as of December 2016. When I asked Debra what she would do if these results come back positive in the eggs, she responded ambiguously but without alarm:

If there's lead in the eggs, I'm not gonna keep eating them and I'm not gonna keep giving them to other people, for sure. And, I don't know, [l'll] take it from there. I would imagine then the meat would also be contaminated, so it's probably not a good idea to eat the chickens either. So l'd probably just keep them, let them eat their own eggs or something.

From her participation in "Legalize Chickens in Boston," Debra remembers the topic of lead in chickens coming up in discussion, though "never with resolution." She told me that she believes the reason for this was the group's focus on the legalization and promotion of chicken keeping: "I think we were not particularly looking for the problems there might be, or looking to raise those. But I think that people were aware of them." Here again, there exists a strange balance between acknowledgement of lead as a potentially serious issue for chicken keeping and an ambivalence towards seriously considering it in conversations about that very practice. Although she had not necessarily expected to find lead in her chickens, Debra holds the same matter-of-fact attitude as Linda and Mary regarding whether this is a topic chicken keepers in the area know about.

I think it should be, because I know there's lead in the soil. And, you know, there is in most urban settings. So unless you've replaced all your soil...it seems pretty certain that there's gonna be some lead out there...[These topics] have been in the back of my mind, so I'm just happy to have people that are looking into it. And it makes a lot of sense for urban chickens.

For Debra, this "common sense" attitude 
towards the potential for lead contamination in urban chickens has implications for weighing the costs and benefits of urban chicken keeping on a larger scale. When telling me about her growing interest in local food production, she made clear that this was not directly because of getting chickens. In fact, she saw her experience with her chickens as a possible reason to critique the idealism of urban chicken keeping:

\section{I mean, actually when I think about the chickens and the lead issue...If the lead is an issue [in my chickens' eggs], then...these things are more complicated than you think. You think 'oh sustainable, all this healthy', then you realize it's not that easy or simple.}

In this part of our conversation, Debra's husband joined our table and replied to his wife with his own sarcastic yet ironically deeply multispecies-oriented insight: "[y]eah, but you're getting the lead out of the soil. It's getting recycled." We all laughed, but Debra's husband made a point few directly invested in this scene seem willing to admit as the current status quo of these backyard ecologies: actual bodies of birds and humans are serving as vessels for the cycling of this lead out of the soil. Within the context of my human-centric interview with Debra on her experience of chicken keeping, her husband's characterization of this situation as two species metabolizing toxic metals together out of the soil could only be tossed into the dialogue as a joke, but this joke stands as the most realistic multispecies and metabolically-aware characterization of the situation I heard during my research.

Finally, John's experience as an urban agriculture store owner provides a unique lens into the responses of many actors in this scene. From the conversations he has had with keepers, he feels the issue of lead in chickens is a worry on "everybody's" mind but manageable through techniques of stricter confinement and raised platforms, methods used by keepers he knows in several Boston neighborhoods. He demonstrated many of the same arguments I heard from my other research participants: keeping your chickens further from your house's edge reduces risk of lead contamination from chipping lead paint; residential keepers are not eating enough eggs to impact their health if the eggs are indeed contaminated; and this is already a topic on keepers' minds enough and too much discussion of it may discourage people from what is inherently a good practice. He noted, “[y]ou don't want to scare people away, but if you're thinking about chickens in your yard, you're already thinking about lead anyway." The actual experiences of keepers in this area however quickly prove these to be dangerous assumptions. Keepers I spoke to found spots of high and low lead levels spread randomly over their yards; most of these keepers are eating eggs at much higher rates than previous studies which focused on community-sharing set-ups to calculate the number of urban-raised eggs eaten daily by residents (Spliethoff et al. 2014); and many keepers expressed surprise at the possibility of lead contaminating their backyard chickens. The numbers of keepers unaware of potential lead contamination in their chickens and eggs are likely even higher among lowerincome, non-English-speaking keepers who are not included in the current Tufts lead study, which has only been able to access the largely white, economically privileged "NUCK" population.

John also provides insight into the responses of researchers and city officials. At one recent Boston conference on urban agriculture and environmentalism, he recalled speakers avoiding or dismissing questions about lead, something he attributes again to a hesitancy he and others feel within the urban agriculture community about scaring people away from "something that is inherently good anyway." I heard this sentiment from many other people including keepers and those who had raised questions with city officials. The responses they received signaled both an unwillingness to tackle the issue directly and a public consensus that further results are needed to assess the situation from $a$ health and environmental perspective.

In focusing my discussion on the issue of lead within Somerville and Boston chicken keeping, I do not aim to paint the situation as a dire public health concern or call for immediate 


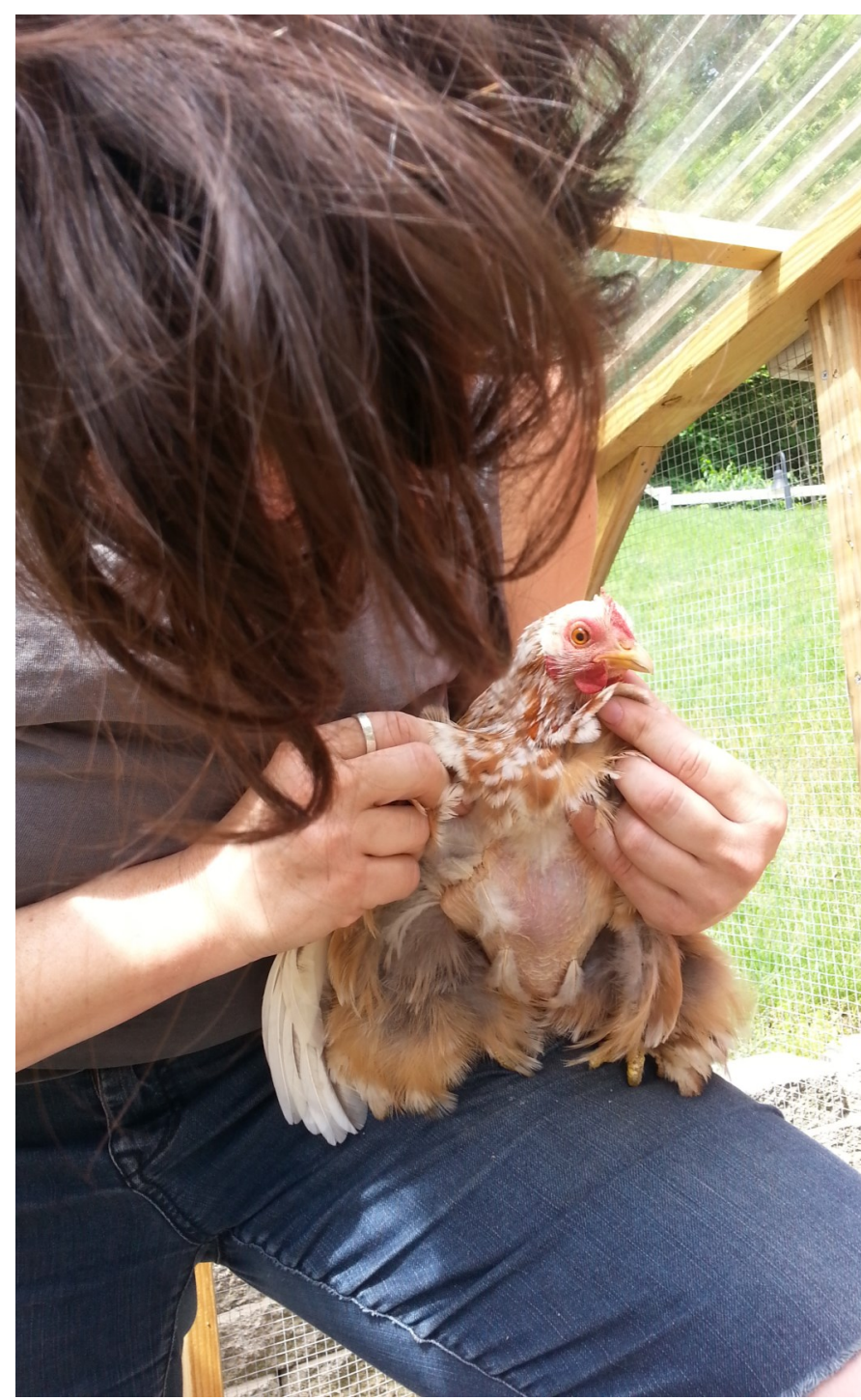

Figure 6: A chicken receives a "health-check" from a local business owner specializing in urban chicken keeping. During the check, the caretaker looks for signs of common chicken illnesses as well as symptoms that may suggest high levels of lead in the chicken's blood due to its urban environment. Photo by author.

policy intervention. There are no US healthbased standards for lead levels in eggs, but studies such as Spliethoff et al.'s (2014) evaluation of lead in community-shared eggs in New York City caution that "any exposure to lead is considered to be potentially harmful to human health since no threshold for adverse effects has been identified" (3). Low levels of exposure combined with the bioaccumulation risk of lead in bones have been linked to nervous system and reproductive health impacts in particular (Spliethoff et al. 2014, 3). These effects are most urgent for children and pregnant women. Still, researchers in the current Tufts study state that for most healthy adults consuming these eggs, a health risk is unlikely even with lead contamination, and for most of these chickens ingesting lead, symptoms seem rare (see Figure 6).

Like many who are involved more directly in this scene, I also feel caution about pushing the lead situation towards an immediate solution that may forgo thinking about how to address the problem while preserving the benefits of urban agriculture felt by these communities. This being said, the ambivalence expressed by keepers combined with the fact that this potential matter of public health is not yet registering as a serious actionable concern among public officials is a collective response that is worth further inquiry. The stalled public response seems to be neither an entirely unwise course of action nor complete blindness to the breakdown of their city's goodwill towards urban agriculture: those within this scene find themselves in some middle ground of wanting to keep space open for urban agriculture's potential while also recognizing that this will provoke unanticipated questions.

As long as the imaginary of the postindustrial city is preserved, Boston and Somerville governments are free from their histories of urban industry and the resulting contamination, and responsibility for any complications encountered by urban neo-agrarians is diffuse and ambiguous. With the concept that we are past the industrial, residents and cities are conceptually off the hook for the industrial history that is still very much part of the place they call home. They are also conceptually and spatially distanced from present economic realities where industrial production has moved elsewhere while their own postindustrial labor enables the simultaneous pursuit of an idealized urban agriculture and an attempted remediation of its biological complications. Within this imaginary, urban agriculture exists as both an attempt to move outside capitalist discourse of food but also an example itself of "spaces of neoliberal governmentality," which shift responsibility for change and costs of reproduction from the public to private sphere (McClintock 2014; 155).

Within a more nuanced view of these cities' soils and bodies as still imbued with industrial legacies, however, the question of responsibility becomes more political. The yard is a marginal space that defies easy classification as a public 
or private sphere, and urban livestock blur more categories and classifications than do tomatoes or kale. Likewise, the consumption of these eggs not only by private homes but also by friends and neighbors through sharing economies blurs the private nature of these residential practices. Could these cities be held responsible for remediating their residents' soil? Does responsibility depend on the source of the lead-home paint contained in a private yard versus a neighborhood's water supply, for example-or does responsibility in this scenario mean something larger, a response that city governments must take if they want to truly make urban agriculture a safe option for all inhabitants-white, black, and brown residents; chickens, sparrows, and hawks, low, middle, and high income? Taking a more nuanced view of urban ecology within this scene requires us to rethink what the complex practice of raising productive animals in the city entails for all bodies involved, what types of care are needed to cultivate new urban relationships with food and other species, and who is responsible for healing the humans, animals, and land caught up in these histories.

The lead situation is unique because more than any other break in the study participants' idealized preconceptions of urban chicken keeping, it has forced urban chicken keepers and their proponents to look critically at what they are attempting to do. In the supposed transition of cities like Boston and Somerville from industrial centers to postindustrial urban ecologies, lead and other residues show how that transition is constructed rhetorically while remaining materially incomplete. These residues-evidences of Haraway's "sticky knots" that attach beings' worlds, and McClintock's material legacies of costs of capitalism not yet fully or justly paid, materializing in the soil, eggs, blood, and bones of these urban agriculture projects-call for acknowledgement of the urban space's history and new investments in the health of the bodies and land involved.

\section{Conclusion}

Increasingly, the question is not whether these keepers and the cities are going to respond to the rifts they are witnessing but rather, how will they respond? There is hesitancy in these stories as to what this reality might mean for urban agriculture's imaginary, but there are also moments of potentially transformative ways of thinking. What would it really entail to recognize the interconnectivity of the city's multispecies ecology? My research reveals a multilayered, complicated, yet unavoidable sense of responsibility to find ways to heal bits of the metabolic rift that has been present since the start of industry and that increasing numbers of city residents are beginning to acknowledge and discuss.

As is evident, the situation is currently swaying back and forth between ambivalent avoidance and opening some kind of responsibility for the histories of this particular place. These margins of becoming worldly and responding exist around these yards, so how do the actors here come to notice them and let them flourish? In other words, how does taking responsibility for our home space and our part in its history and future change when this realm now includes a landscape? The responses of this developing scene give some hope that when categorizations of place, home, and care themselves blur lines around domesticity, new spaces open up for becoming worldly with others. Nading states that "people negotiate and redefine health as they...develop and deploy knowledge about what kind of life...is worth monitoring, preserving, and reproducing" (2014, 11). Keepers and proponents are having to grapple with this question of their larger ecosystem's metabolic health; for the healthy, green city, each cog in its metabolic wheel from the human to the microbes in the soil must be considered. Response cultivates further response, gathering up beings into "unpredictable kinds of 'we"' (Haraway 2007; 5) in multispecies cohorts implicated together and therefore invested together in remediating bits of these histories.

What are the stakes of forging a new sort of multispecies solidarity in these responses, and where does this responsibility for making these responses lie? Is there space for transformative and just ecological thinking to matter here, even with frequently voiced concerns that these types of conversations may hurt the positive image of urban agriculture? My aim through 
this analysis is to assert that the answer to this question can be nothing other than a resounding "yes" if urban agriculture hopes to have any of the lasting, significant, and just impacts its proponents aim for it to have in food system and larger urban change. The discovery of lead in Somerville and Boston's urban chicken coops has been able to break through the imagined linear progression of these historied spaces and provide a "potential point of engagement" (McClintock 2010, 13) for more nuanced conversation about urban agriculture's position within not only imaginary but truly embodied multispecies relationships with food and urban life. Neo-agrarian urban chicken keepers have begun to and will increasingly be forced to grapple with conversations around embodied material legacies, responsibility for ecological remediation, and multispecies solidarities and sovereignties. In doing so, they may transform visions of what true urban neo-agrariansm entails for the land and bodies implicated in this movement. 


\section{Acknowledgements}

I would like to thank my interview participants for their contributions to this research and willingness to connect me with others in this scene. I would also like to thank my faculty advisor, Cathy Stanton, for her teaching and guidance throughout my research and writing process. Lastly, I would like to thank the Tufts Summer Scholars program, Anne Moore, and Ashley Wilcox for mentorship and funding over the course of my research. 


\section{References}

Alkon, Alison Hope., and Julian Agyeman. 2011. Cultivating Food Justice: Race, Class, and Sustainability. Cambridge, MA: MIT.

Barth, Brian. 2015. "5 Top Cities for Raising Urban Livestock." Modern Farmer, April 10. Accessed January 15 2015. http://

modernfarmer.com/2015/01/5-top-cities-raising-urban-livestock/.

Blecha, Jennifer Lynn. 2007. Urban Life with Livestock: Performing Alternative Imaginaries through Small-Scale Urban Livestock Agriculture in the United States. PhD diss., University of Minnesota.

Bluestone, Barry, and Mary Huff Stevenson. 2000. The Boston Renaissance: Race, Space, and Economic Change in an American Metropolis. New York: Russell Sage Foundation,

Haraway, Donna J. 2008. When Species Meet. Minneapolis: University of Minnesota Press.

Marx, Karl. 1981. Capital: A Critique of Political Economy, vol. 3. London: Penguin Classics.

McClintock, Nathan. 2014. "Radical, Reformist, and Garden-Variety Neoliberal: Coming to Terms with Urban Agriculture's Contradictions." Local Environment: The International Journal of Justice and Sustainability. 19(2): 147-171.

McClintock, Nathan. 2010. "Why Farm the City? Theorizing Urban Agriculture through a Lens of Metabolic Rift." Urban Studies and Planning Faculty Publications and Presentations. Paper 91: 1-17.

Moore, Lisa Jean, and Mary Kosut. 2013. "Among the Colony: Ethnographic Fieldwork, Urban Bees and Intraspecies Mindfulness." Ethnography15 (4): 516-539.

Moore, Sarah. 2006. "Forgotten Roots of the Green City: Subsistence Gardening in Columbus, Ohio, 1900-1940." Urban Geography 27 (2): 174-92.

Nading, Alexander M. 2014. Mosquito Trails: Ecology, Health, and the Politics of Entanglement. Oakland: Univerity of California Press.

Rudy, Kathy. 2011. Loving Animals: Toward a New Animal Advocacy. Minneapolis: University of Minnesota Press.

Spliethoff, Henry M., Rebecca G. Mitchell, Lisa N. Ribaudo, Owen Taylor, Hannah A. Shayler, Virginia Greene, and Debra Oglesby. 
2014. "Lead in New York City community garden chicken eggs: influential factors and health implications." Environmental Geochemistry and Health 36 (4):633-649.

Stanton, Cathy. In press, 2017. “Keeping 'the Industrial': New Solidarities in Post-Industrial Places" in The Deindustrialized World: Confronting Ruination in Postindustrial Places. Steven High, Lachlan MacKinnon, and Andrew Perchard, eds. Vancouver: University of British Columbia Press.

Steinberg, Ted. 2002. Down to Earth: Nature's Role in American History. Oxford: Oxford University Press.

Tsing, Anna. 2012. "Unruly Edges: Mushrooms as Companion Species." Environmental Humanities 1: 141-154.

Voigt, Kate A. 2011. "Pigs in the Backyard or the Barnyard: Removing Zoning Impediments to Urban Agriculture." Boston College Environmental Affairs Law Review537-566.

Stephen V. Ward. 1998. Selling Places: The Marketing and Promotion of Towns and Cities 1850-2000. London and New York: Routledge. 